\title{
O direito à vida na conjuntura da distanásia
}

\author{
DOI: $10.47224 /$ rm.v6i10.95
}

\author{
Sueli de Fátima Marques Parreira \\ Jucielle Costa Silva \\ Lucas Gabriel Sousa Santos
}

e-mail: suelimarques27@gmail.com

\begin{abstract}
Resumo
O presente estudo trata-se de uma revisão narrativa tradicional acerca do tema dos impasses do direito à vida na conjuntura da distanásia. Com o objetivo de compreender, judicialmente, a realidade do direito à distanásia enquanto uma garantia ao bem absoluto da vida de indivíduos dependentes do Sistema Único de Saúde (SUS), recorreu-se a artigos acadêmicos produzidos nas últimas décadas acerca do assunto. Analisou-se, qualitativamente, a literatura encontrada, com a finalidade de ampliar os conhecimentos sobre a temática abordada, e, para isso, foram utilizadas, como descritores, as palavras: "desocupação de leitos", Direito, distanásia, "Justiça brasileira" e SUS. Os resultados evidenciaram a responsabilidade preponderante da Justiça brasileira na prática do direito à vida, bem como diversas situações nas quais este não foi garantido. Com exemplos nacionais e mundiais, percebeu-se a divergência de opiniões e argumentações que tem gerado, ao longo de décadas, o impasse desse direito, tanto no âmbito jurídico, quanto no médico. Em um Sistema que não suporta uma assistência integral à população, pessoas com pouca chance de vida, que ocupam leitos no SUS, geram gastos onerosos e, por isso, não são vistas com bons olhos pelo Governo, que tenta priorizar indivíduos mais "saudáveis", como se o direito à vida só valesse a estes.
\end{abstract}

Palavras-chave: "Desocupação de leitos", Direito, Distanásia, “Justiça Brasileira”, SUS

\begin{abstract}
The present study is a traditional narrative review on the issue of impasses in the right to life in the context of dysthanasia. In order to understand, judicially, the reality of the right to dysthanasia as a guarantee for the absolute good of life of individuals dependent on the Unified Health System (SUS), academic articles produced in the last decades on the subject were used. The literature found was analyzed qualitatively, with the purpose of broadening the knowledge on the theme addressed, and, for this purpose, the infringing keywords were used as descriptors. The results showed the preponderant responsibility of the Brazilian Justice in the practice of the right to life, as well as several situations in which it was not guaranteed. With national and global examples, it was noticed the divergence of opinions and arguments that it has generated, over the decades, the impasse of this right, both in the legal and in the medical sphere. In a System that does not support comprehensive assistance to the population, people with little chance of life, who occupy beds in the SUS, generate costly expenses and, therefore, are not welcomed by the Government, which tries to prioritize more "healthy" individuals, as if the right to life only.
\end{abstract}

Keywords: $\quad$ Keywords: “emptying of beds", Law, dysthanasia, "brazilian Justice”, SUS.

\section{INTRODUÇÃO}

A sociedade é permeada por mudanças estruturais, culturais, psicológicas e legais. Por ser alvo de constantes estudos e progressos científicos, muitas leis surgem e são combatidas perante interpretações jurídicas que se fundamentam no que consideram o legal para o corpo social. Nesse ínterim, polêmicas, como a atitude governamental diante da distanásia no Sistema Público de Saúde, alegram ou revoltam estudiosos. Dessa maneira, torna-se fundamental entender qual é a responsabilidade de um juiz em questões de indivíduos em distanásia no Sistema Único de Saúde (SUS). Por isso, objetiva-se, com essa narrativa, revisar conceitos e discussões do tema proposto em prol de fomentar a reflexão dessa 
realidade dentre pósteros magistrados os quais poderão intervir, futuramente, em situações desse gênero. Com esse fim e em benefício de argumentar quanto à distanásia no campo jurídico, supõe-se que o encargo judicial sobre a vida de uma pessoa, impossibilitada ou não de responder por si, seria o de garantir que ela tenha acesso a todo artifício possível para a preservação de sua vida. No entanto, essa não é a realidade que predomina no Brasil, onde o Sistema Público é, por vezes, precário ou insuficiente para atender a todas as necessidades salutares da população.

Outrossim, o que se percebe é que tem surgido, cada vez mais, métodos terapêuticos artificiais que evitam a morte de um paciente, os quais podem ou não aliviar o sofrimento deste. Porém, apesar do avanço tecnológico proeminente, muitas vezes, cabe ao médico ou ao jurista decidir a quem este irá, ou não, servir, o que leva a uma indispensável meditação no campo jurídico em relação à distanásia.

Apreende-se, desta forma, que a dicotomia do direito à vida e da morte digna recebe diversas exposições que se confrontam em algo primordial que é o próprio conceito de "vida". Enquanto alguns autores acreditam que a distanásia "[...] é a extensão da morte mediante o uso de meios extraordinários e desproporcionais, que propiciam um aumento da quantidade de vida, sem contribuir para a melhora da qualidade de vida do enfermo" (ABREU; BARBOZA, 2018, p.46), ou que ela é sinônimo de obstinação terapêutica (SILVA, 2016), grande parte da população a escolhe como primeira opção para conduta a um familiar (SILVA et al., 2014). E, com isso, surge uma grande divergência entre literatos que exploram a morte e a vida a partir da medicina, escritores que falam sobre o que o termo "distanásia", gramaticalmente, significa e pessoas que não têm conhecimento teórico do assunto, mas que, vivenciando uma condição familiar de distanásia, elegem-na como o melhor caminho a ser seguido para as pessoas as quais amam.

Destarte, nessa adversidade de opiniões e pensamentos, é de suma importância que os profissionais do Direito estejam preparados e respaldados para lidarem com os dispositivos legais que regulamentam ou não a prática da distanásia, pois é por intermédio da orientação e da rediscussão fundamentadas pela legislação brasileira que os futuros legislados poderão lidar humanamente e legalmente com impasses que abranjam, por exemplo, um leito que precisa ser desocupado para salvar uma vida, e que não o é ou é porque ampara uma pessoa em distanásia: um caso que indigna sempre um lado das famílias envolvidas e que coloca em pauta se os direitos à vida estão sendo preservados ou não já que não há um consenso nem mesmo dentro do campo judicial. E isto revela, pois, a atualidade do tema explanado, na qual o público interessado não seria somente os estudantes de Direito, mas a própria sociedade que enfrenta um Sistema Público de Saúde que coloca médicos e juízes diante de apuramentos e critérios de preferência num contexto em que, pela Constituição, todos deveriam ter os mesmos direitos à vida e à dignidade. Por conseguinte, uma exposição em prol do esclarecimento do que, judicialmente, está sendo acatado como preservação do direito à vida, possui um potencial de ação de informação, de debate e de conscientização acadêmica, o que, por sua vez, pode contribuir para melhorar esse cenário de dúvidas, inconsistências e adversidades.

\section{DISTANÁSIA: CONTROVÉRSAS BRASILEIRA}

A distanásia, no Brasil, é permeada por uma realidade contraditória, na qual a legislação nacional, os pesquisadores, os médicos, os juízes e a população brasileira se contradizem em pontos de vista e amparos divergentes. Há diversos questionamentos, de tal forma, quando há alguém em distanásia que precisa de leito e tecnologia para sobreviver e que se encontra em um Sistema Público de Saúde que não Ihe coloca como prioridade, cabendo ao médico ou ao juiz decidirem a aplicação de seu direito teórico. Nesse ínterim, surgem justificativas contra e a favor da distanásia que se escoram em conceitos como o da "dignidade" e da "vida". Assim, vale destacar que esta é o maior bem que as pessoas podem ter, motivo pela qual a Constituição Federal do Brasil destaca a sua inviolabilidade e a sua garantia desde o momento da concepção do ser. Igualmente, merece respeito a decisão de poder prolongar a vida o máximo possível e de buscar isto junto ao Estado, já que os direitos da personalidade não são passíveis de limitação voluntária, e a lei brasileira é pautada na igualdade de acesso, bem como na universalidade deste para a devida proteção da saúde enquanto direito de todos.

Não obstante, o Estado declara que não dispõe de recursos financeiros para atender com eficácia a demanda ao prolongamento da vida, e, quando se analisa a situação, infere-se que o problema crucial, muitas vezes, permeia a omissão de uma política social que não desenvolve sua obrigação constitucional. 
Destarte, há uma realidade com muitos problemas sociais em meio a leis e consensos, tais como o do Conselho Econômico e Social (ECOSOC), órgão coordenador do trabalho econômico e social da Organização das Nações Unidas (ONU) e que defende que é imprescindível a garantia mais plena possível do direito à saúde. Também, o repasse de dinheiro destinado à saúde, por parte do Governo, obedece a um limite orçamentário que é insuficiente em termos nacionais. Avaliando-se acerta disto tudo, há os magistrados, que devem julgar as solicitações de tutela cingindo casos de distanásia no SUS, o que, obviamente, é difícil, uma vez que, se não existem leitos para amparar a demanda social, tal tutela perde o seu sentido. As pessoas, no âmago de tanta controvérsia, acionam o poder Estatal para que este, em decisão conjunta a todos os órgãos competentes para tomada de decisões, apresente projetos concretos para os conflitos apresentados. Esperam que medidas judiciais no campo da saúde sejam tidas como urgentes e essenciais, pois se a vida do ser humano possui toda e qualquer prioridade em distintas áreas, então cabe ao Estado fazer valer tais direitos, levando em conta o Direito e a Medicina, o que conduz à questão de como o biodireito e a bioética se posicionariam perante essa situação. Ademais, como a própria legislação brasileira é utilizada perante a lacuna perdurante entre a sua teoria e a sua prática e como a distanásia é vista dentre tantos confrontos são indagações que engendram à indigência essencial de expor, inicialmente, o teor constitucional do país.

A Constituição Federal do Brasil de 1988 institui o direito à vida e à dignidade. No entanto, ela não considera a morte enquanto um item a ser especificado. Consequentemente, com essa indefinição perante à sociedade, o mundo depara-se com debates éticos, humanos e legais de pacientes que se encontram em UTIs em estado de coma ou em fase terminal. Todavia, uma questão primordial é o que a própria Medicina classifica como um paciente terminal. Conforme França $(1999$, p.75) já afirmava:

Definir paciente terminal não tem sido tarefa tão fácil como aparentemente pode dar a entender. Inclusive a expressão terminal, no presente momento, é complexa e arriscada, porque um paciente portador de uma enfermidade de evolução fatal e grave pode, em determinados instantes, voltar às suas atividades, como, por exemplo, os portadores de neoplasias mais severas que têm uma sobrevida estimável - às vezes por tempo prolongado, graças ao avanço vertiginoso das terapêuticas hoje empregadas. Seu conceito, portanto, é impreciso, até porque a própria vida já é por si mesma terminal.

Desse modo, os médicos, os legisladores e a sociedade enfrentam um dilema carregado de decisões legais, sociais e conceituais relativamente à distanásia. Muitos defendem o que Lacerda et al. (2015) citam como a "morte digna", o que, por sua vez, é apreciada por outros como sinônimo do assassinato da pessoa humana.

Nesse viés, sabe-se que a morte, no mundo contemporâneo, apesar de ter o seu aspecto humano, é ligada à indústria e ao capitalismo que se por um lado busca o enfrentamento de doenças e a qualidade de vida, por outro, em se tratando do Sistema Único de Saúde, quer "poupar" gastos para quem "realmente precisa". O setor industrial cobra um alto preço para o prolongamento da vida, o qual, muitas vezes, o Governo não quer gastar, já que há outras prioridades. Nesse sentido, enquanto uma intensificação em favor da vida no SUS, a distanásia promove o que Pessini (2009) refere ser o empenho da medicina em retardar a morte em contraposição com os gastos onerosos que incomodam o Governo para na manutenção da saúde pública. Consequentemente, questões éticas e morais configuram o cotidiano de profissionais da saúde que ora temem enfrentar um processo legal por negligência (FERREIRA; SOUZA; LIMA, 2011) ou por suas ações serem interpretadas como prática da eutanásia (que é a morte provocada e é proibida no Brasil) ora temem enfrentá-lo por gerar gastos públicos tidos como desnecessários. Afinal, como um ser humano, por mais conhecimento que tenha, pode afirmar que a morte de alguém é inevitável? É claro que existem indícios, mas, na Medicina, indícios podem levar a desfechos inesperados.

Além disso, mesmo que a distanásia estenda a vida do paciente à custa, por vezes, da qualidade, é preciso lembrar que muitos pacientes ou representantes destes optam e desejam pelos procedimentos desta (CRUZ; OLIVEIRA, 2013) na esperança de uma cura ou de uma melhora, e isto não pode ser desconsiderado, já que a vida, como a legislação brasileira prega, é um direito fundamental.

Nessa conjuntura, diversos são os casos de legisladores, escritores e profissionais da saúde que se contradizem, bem como de médicos que enfrentam a Justiça no âmbito da Saúde Pública no Brasil. A Justiça e a Medicina brigam, dessa forma, há décadas em uma luta na qual não há ganhadores eternos. À vista disso, em 2006, o Conselho Federal de Medicina 
(CFM) aprovou uma resolução que permitia, aos médicos, a interrupção de tratamentos que estariam prolongando a vida de doentes em estado terminal, com a ressalva de que esta disposição teria que ser a vontade explícita do próprio doente ou de seus familiares (Resolução CFM no 1.805/2006, publicada no D.O.U., 28 nov. 2006, Seção I, pg. 169). Esta pareceu uma decisão sensata em termos de Saúde e de Justiça, a qual, entretanto, foi suspensa, posteriormente, por decisão liminar do M. Juiz Dr. Roberto Luís Luchi Demo, nos autos da Ação Civil Pública, sob a justificativa de que o Conselho Federal de Medicina não teria poder regulamentar para estabelecer como conduta ética uma conduta tipificada como crime.

Depois, em 2011, o Ministério Público Federal na Paraíba (MPF/PB) ajuizou uma ação civil pública com pedido de liminar contra a União para transferir uma paciente de 3 anos e 11 meses, portadora da síndrome de Werdnig-Hoffman, que estava ocupando um leito de UTI há três anos e 5 meses, para um serviço de atendimento de cuidados paliativos ou destinado a pacientes terminais, serviço este que não havia na Paraíba. Nas palavras do procurador da República Duciran Farena, que assinou a ação, por pura ineficiência do Sistema Único de Saúde, um leito de UTI, cuja manutenção custaria milhares de reais em uma gravíssima crise de falta de leitos, estaria sendo mantido ocupado por uma paciente que deveria receber atendimento domiciliar e cuidados paliativos de custos infinitamente inferiores, bastando equipamento de suporte ventilatório, medicamentos, material descartável e visitas periódicas de pessoal médico especializado (JUSBRASIL, 2011).

O curioso é que a preocupação do procurador, nitidamente, estaria sendo com os gastos públicos aplicados a essa criança que deveria desocupar um leito para, ao receber cuidados paliativos, obviamente, ir a óbito. Isto remete instintivamente à memória do que Fernandes (2016) discorreu como sendo o mundo atual agindo como uma "Esparta do mundo moderno", posto que pacientes terminais ou em condições difíceis de vida estariam sendo "descartados", impossibilitados de cuidados por causa do desdém de profissionais e dos poderes públicos.

Ou seja, uma criança que ocupa um leito estando com uma doença predita como terminal teria menos direito do que outra com uma saúde melhor, já que alguém que aos olhos do procurador já está com a morte certa não pode fazer o Governo gastar dinheiro com sua vida. Seria a "avançada" cultura hodierna que, segundo o advogado, valorizaria apenas o utilitarismo, o ser humano com potencial econômico e saúde.

Como exemplo disto, há quase uma década, houve, no Brasil, mais um dentre tantos casos de médicos que decidiram, em prol de liberarem leitos (em conformidade com a opinião do procurador supracitado), descumprirem a resolução de 2006, o que culminou, dentre outros casos, em uma denúncia, em 2013, concernente à conduta da médica Virgínia Soares de Souza e de outras sete pessoas subordinadas a ela, acusadas de antecipar a morte de pacientes internados na Unidade de Terapia Intensiva (UTI) do Hospital Evangélico, no Estado do Paraná. Absurdamente e a despeito da revolta dos familiares, o juiz Daniel Surdi Avellar, da 2a Vara do Tribunal do Júri de Curitiba, inocentou os acusados por falta de evidências (G1, 2017).

Já em 2016, O Conselho Federal de Medicina voltou a se pronunciar no dilema médico jurídico dos pacientes em distanásia nos hospitais públicos do Brasil, recomendando que pacientes sem possibilidade de recuperação fossem transferidos de Unidades de Terapia Intensiva para áreas de cuidados paliativos em benefício de reduzir os efeitos da falta de leitos de UTI no País (O Estado de S. Paulo, 2016). A decisão gerou apoios e críticas numa dinâmica legal que persevera com relação ao que a Constituição preconiza versus ao que os legisladores e os profissionais da saúde interpretam como "direito" e "vida".

\subsection{MAGISTRADOS EM MEIO À BIOÉTICA E AO BIODEIREITO}

Com esse panorama de divergências que permeia a distanásia no SUS, é preciso que haja uma ponderação coletiva do papel essencial que a jurisprudência do Supremo Tribunal Federal tem no amparo aos pacientes em distanásia, uma vez que uma ação precipitada pode resultar em um óbito que poderia ter sido evitado. De tal modo, é preciso que haja coerência dos entes públicos ao falar de distanásia, pois é contraditório o investimento em áreas que poderiam esperar em contraponto com a negligência que ocorre quando se fala em saúde pública. $O$ Governo não se incomoda em pagar bilhões por ano em auxílios paletós, mas se importa em mover uma ação para tirar uma criança de três anos de um leito público, porque essa criança tem que ir para casa morrer ao invés de gerar gastos públicos tentando sobreviver. 
É claro que há muitas variáveis que devem ser examinadas, como a vontade do paciente ou da família, mas, a priori, ninguém deveria ser obrigado a deixar um recurso terapêutico por estar em distanásia com a justificativa disso estar sendo oneroso para o Estado, pois tal fato implica no ferimento do direito fundamental que todo ser humano tem que é o direito à vida em condições de igualdade.

O que se percebe é que os poderes públicos são dinâmicos em arrecadar impostos e inoperantes em retribuí-los ao benefício social, sendo que "um paciente terminal que se encontra na Saúde Pública Brasileira, não raras as vezes, é vítima metaforicamente de um 'holocausto nazista' por estar exposto aos corredores e por padecer de forma atroz sem que ninguém o "socorra" (FERNANDES, 2016). Argumentadores acerca do biodireito e da bioética enfrentam, portanto, um grande desafio frente à pedida de desocupação de leitos de pacientes em distanásia no SUS.

A bioética ou "ética da vida" é uma ciência que "tem como objetivo indicar os limites e as finalidades da intervenção do homem sobre a vida, identificar os valores de referência racionalmente proponíveis, denunciar os riscos das possíveis aplicações" (LEONE; PRIVITERA; CUNHA, 2001), e é usada por quem quer a desocupação de leitos como justificativa para tal.

Argumenta-se, a este favor, que pessoas que estão em fase terminal de vida ou com poucas chances de sobrevivência não devem receber mais intervenções, em prol da bioética. Enquanto isso, o biodireito, que se integra à bioética, serve para analisar as relações jurisdicionais entre o Direito e a tecnologia avançada na Medicina, com as mais variadas particularidades pertinentes à vida e à dignidade do indivíduo.

Em meio a isto, muitos juízes, entendendo a bioética e o biodireito como garantias da vida humana, enfrentam os possíveis confrontamentos sociais em prol da vida alheia. E isto não circunda apenas casos de distanásia. Recentemente, em 2019, contrariando a decisão dos pais, Testemunhas de Jeová, o juiz Clauber Costa Abreu, da 15a Vara Cível e ambiental de Goiás, ordenou a transfusão de sangue para a bebê que nasceu prematura (LEIA JÁ NACIONAL, 2019).

O fato gerou a mesma polêmica que é gerada quando juízes decidem a favor ou contra a distanásia, justamente porque encerra não somente as leis brasileiras, mas a medicina, o biodireito, a bioética.

Igualmente, para alcançar-se uma decisão, os jurídicos amparam-se na biomedicina, como reguladora natural da saúde e do bem-estar das pessoas, e nas limitações ditadas pela aplicação do direito consuetudinário. Consoante Barboza (2009, p. 212) afirma:

A difícil tarefa de estabelecer esses valores tem sido desempenhada pelo Direito, embora o rápido desenrolar dos acontecimentos, não raro atropele o ordenamento, exigindo do jurista esforço interpretativo para adequar as normas existentes às novas situações, mantendo íntegro o sistema vigente, fato que tem se acentuado nas últimas décadas, graças ao acelerado desenvolvimento tecnológico e biomédico [...] Cabe ao direito, por meio de lei, entendida como expressão da vontade da coletividade, definir a ordem social, na medida em que dispõem dos meios próprios e adequados para que essa ordem seja respeitada.

Assim sendo, o direito à saúde não se limita à prevenção de enfermidades, mas em garantia de vida. Esse direito está conectado ao fato original da vida, ou seja, nascer-viver-morrer, mas como cada um vai chegar ao término deve ser de liberdade de predileção individual, observando-se a garantia de oferta a todos os métodos possíveis para se manter a vida.

Afinal, os casos aclarados no decorrer dessa narrativa foram alguns dos diversos que ocorrem diariamente no Brasil e que elucidam que a defesa da permanência da vida como prioridade é um direito-dever de todo indivíduo. Infelizmente, apesar de a lei ser clara quanto a isso, ainda não subsiste um consenso nacional. A distanásia, no Brasil, é um dilema público que não foi suficientemente esmiuçado para se chegar a uma solução, uma vez que abarca múltiplas áreas, estudos e conceitos. A nível mundial, não é diferente.

Constantemente, vê-se casos de comoção pública envolta de pais que, literalmente, enfrentam uma luta diária na defesa da vida de seus filhos em distanásia. Os pais do bebê Alfie, por exemplo, são um grande exemplo de seres humanos que defenderam a distanásia até o último recurso por amor e defesa da vida do filho.

Eles receberam apoio global, contaram inclusive com a solidariedade do Papa Francisco e do governo da Itália, os quais fizeram o possível para que o bebê recebesse todo o recurso possível para sua sobrevivência e para que os pais fossem amparados em seus direitos de buscarem novos tratamentos. Lamentavelmente, a decisão final coube a um juiz britânico que pôs fim a essa saga, desautorizando os pais a viajarem para Roma com seu filho em busca de uma nova terapia e determinando que os sistemas de 
suporte vital fossem retirados da criança (ISTOÉ, 2018).

Bioética? Biodireito? Biomedicina? Prolongamento da dor? Prolongamento da vida? Direito à vida? Esperança? Amor? Quem tem conhecimento para garantir que alguém não tem chances de sobreviver se há casos de pessoas "terminais" que voltam a ter uma vida saudável? Quem tem o direito de determinar ou tirar um direito? Um juiz, uma sentença, uma vida!

\section{CONSIDERAÇÕES FINAIS}

O direito à Distanásia é controverso, conquanto devesse ser aceito como devido alvedrio, seja do paciente em plena consciência, seja de seus familiares, sem imposição alguma da esfera governamental ou de outros, para resguardar-se a autonomia da vontade do indivíduo.

Em face ao exposto, percebe-se que casos de distanásia não são priorizados e nem vistos como direito fundamental à vida, o que contraria a Constituição Federal Brasileira que garante a vida como um dever propriamente do Estado e um direito de todos, carecendo de ser afirmada por diversas políticas públicas, econômicas e sociais. Inúmeros são os casos de distanásia levados ao extremo da luta judicial no Brasil e que não foram citados nessa narrativa.

A título de exemplo, aludiu-se exclusivamente alguns mais destacados pela mídia e que engendram a consciência de que há uma garantia teórica da população ser cuidada pelos poderes públicos e que estes têm o dever de tratar em parâmetros de igualdade qualquer enfermo, seja em caso grave ou não, terminal ou não, custoso ou não.

Nesses termos, independe o estado de saúde do indivíduo, pois sua dignidade é intrínseca ao seu ser, que não pode sofrer preconceito social ou legislativo. Nessa sequência, vale compreender os limites das normas jurisdicionais e dos conceitos de estudiosos quando há uma grande probabilidade de familiares ou do próprio paciente consciente manifestarem suas vontades no que tangem aos tratamentos e às tecnologias que lhes podem ser aplicadas.

Afinal, a partir de um diagnóstico de pouca perspectiva de cura ou da própria vida e do que alguns afirmam ser o prolongamento da existência humana, há a livre escolha garantida pela Constituição Federal e o princípio da universalidade do acesso aos serviços de saúde em TODOS os níveis, garantido pelo art. 70 da Lei 8080/90, confirmando a saúde como o direito social. Confrontar esse direito com conceitos do que é a vida, ou a dignidade, ou com o significado de "distanásia" é renegar o próprio direito.

Por isso, se Sarah Westphal afirma que "[...] embora quem quase morre esteja vivo, quem quase vive, já morreu", deve-se lembrar que quem está em situação de distanásia NÃO morreu, e, sendo assim, ainda deve ter seu direito à vida preservado.

Nesse contexto, é de suma importância que o judiciário não cometa injustiças no tocante à distanásia e que, perante conflitos de orçamento e saúde, opte por este último, uma vez que "o estado de saúde de uma pessoa não deve ser critério de seletividade para decidir quem possui o direito de viver" (FERNANDES, 2016) e que o direito à vida e às outras garantias fundamentais não devem ser suprimidos.

\section{REFERÊNCIAS}

ABREU, C. B.; BARBOZA, H. H. Responsabilidade pela Distanásia na Saúde Privada. Revista Interdisciplinar de Direito, v. 15, n. 2, p. 45-62, 2018.

BARBOZA, H. H. Princípios da bioética e do biodireito. Revista Bioética, v. 8, n. 2, 2009.

BRASIL. Constituição (1988). Constituição da República Federativa do Brasil. Brasília, DF: Senado Federal: Centro Gráfico, 1988.

CATÃO, M. do Ó. Genealogia do Direito à Saúde: uma reconstrução de saberes e Práticas na modernidade. 21 ed. Campina Grande: EDUEPB, 2011.

CFM recomenda que paciente terminal seja transferido de UTI para área de cuidados paliativos.

O Estado de S. Paulo, 2016. Disponível em https://saude.estadao.com.br/noticias/geral,cfmrecomenda-que-paciente-terminal-seja-transferidode-uti-para-cuidados-paliativos, 10000089037.

Acesso em 26 de abril de 2020.

CRUZ, M. L. M. da. OLIVEIRA, R. A. de. A licitude civil da prática da ortotanásia por médico em respeito à vontade livre do paciente. Revista Bioética. (Impr.). 2013; 21 (3): 405-1.

FERNANDES, Álvaro Felipe Câmara da Silva. O Direito Fundamental à saúde e a obrigação de fazer do Estado no tratamento paliativo dos pacientes terminais. 2016. TCC. Faculdade Farias Brito, 2016. 
FERREIRA, A P. de J.; SOUZA, L. J. de; LIMA, A. A. de F. $O$ profissional de saúde frente à distanásia: uma revisão integrativa. Bioethikos, v. 5, n. 4, p. 462-469, 2011.

FRANÇA, G. V. de. Eutanásia: um enfoque éticopolítico. Revista Bioética, p. 71-82, 1999.

JUIZ contraria pais e ordena que bebê receba sangue. LeiaJa Nacional. 2019. Disponível em https://www.leiaja.com/noticias/2019/03/07/juizcontraria-pais-e-ordena-que-bebe-receba-sangue/. Acesso em 27 de abril de 2020.

JUIZ inocenta médica acusada de matar pacientes em UTI de hospital em Curitiba. G1, 2017. Disponível em https://g1.globo.com/pr/parana/noticia/juizinocenta-medica-acusada-de-matar-pacientes-emuti-de-hospital-em-curitiba.ghtml. Acesso em 15 de abril de 2020.

LEONE, S.; PRIVITERA, S.; CUNHA, J.T. (Coords.). Dicionário de bioética. Aparecida: Editorial Perpétuo Socorro/Santuário, 2001.

MPF/PB ajuíza ação para garantir cuidados paliativos à criança em fase terminal. JusBrasil, 2011.

Disponível em

https://mpf.jusbrasil.com.br/noticias/2762009/mpfpb-ajuiza-acao-para-garantir-cuidados-paliativos-acrianca-em-fase-terminal?ref=amp. Acesso em 25 de abril de 2020.

PAIS do bebê terminal Alfie perdem recurso para levá-lo a Roma. ISTOÉ, 2018. Disponível em https://istoe.com.br/justica-britanica-rejeita-ultimorecurso-dos-pais-do-pequeno-alfie/. Acesso em 27 de abril de 2020.

PESSINI, L. Distanásia: até quando investir sem agredir? Faculdade de Medicina da Universidade de São Paulo. 2009.

RESOLUÇÃO CFM № 1.805/2006. Publicada no D.O.U., 28 nov. 2006, Seção I, pg. 69. Disponível em http://www.portalmedico.org.br/resolucoes/cfm/20 07/111 2007.htm. Acesso em 25 de abril de 2020.

SILVA, M. da. Reflexões legais e bioéticas sobre a terminalidade da vida: um estudo sobre ortotanásia e a distanásia diante do direito brasileiro. 2015. TCC. Universidade do Extremo Sul Catarinense, 2015.

SILVA, José Antônio Cordero da Silva et al. Distanásia e ortotanásia: práticas médicas sob a visão de um hospital particular. Revista Bioética. 2014; 22 (2): 358-66.

WESTPHAL, Sarah. Quase. 2005. Disponível em https://www.pensador.com/frase/MjExMjE/. Acesso em 29 de abril de 2020. 